\title{
REABILITAÇÃO VOCAL DO LARINGECTOMIZADO: CARACTERÍSTICAS CULTURAIS DO PROCESSO
}

\author{
Patrícia Gonçalves Custódio Flávio* \\ Márcia Maria Fontão Zago**
}

FLÁVIO, P.G.C.; ZAGO, M.M.F. Reabilitação vocal do laringectomizado: características culturais do processo.

Rev.latino-am.enfermagem, Ribeirão Preto, v. 7, n. 2, p. 63-70, abril 1999.

O objetivo do estudo foi identificar as características do processo de reabilitação vocal entre os laringectomizados, sob o enfoque da cultura. Participaram do estudo quatro laringectomizados que freqüentam o GARPO-Laringectomizados (Grupo de Apoio e Reabilitação de Pessoas Ostomizadas-Laringectomizados) que se comunicam com a voz esofágica ou a voz faríngea. O tema emergente das entrevistas foi "nascer de novo". Com esta frase os laringectomizados expõem a valorização cultural da voz, concordante com o padrão cultural vigente na sociedade ocidental. O estudo revelou ainda as situações de dificuldades, a importância da participação da família, o processo de enfrentamento do estigma da imagem corporal alterada e da afonia.

UNITERMOS: reabilitação vocal, paciente laringectomizado, voz esofágica

\section{INTRODUÇÃO}

Com a finalidade de promover e apoiar a reabilitação do laringectomizado, o Grupo de Apoio e Reabilitação de Pessoas Ostomizadas (GARPOLaringectomizados) iniciou suas atividades em 1990. O grupo é multiprofissional, constituído por enfermeiros docentes e assistenciais, alunos de enfermagem, fonoaudióloga e assistente social, integrados à Escola de Enfermagem de Ribeirão Preto-USP e ao Hospital das Clínicas da Faculdade de Medicina de Ribeirão PretoUSP. Os laringectomizados e seus familiares são provenientes da instituição hospitalar acima referida. $\mathrm{O}$ grupo caracteriza-se por ser aberto, e no período de internação, todos os pacientes e seus familiares são convidados a participar das reuniões mensais.

Na nossa convivência com o grupo, percebemos que o processo de reabilitação dos laringectomizados depende de muitos aspectos: da sua personalidade, da percepção da sua imagem corporal alterada, da condição física pós-operatória, da rede de apoio disponível. Seus conhecimentos, valores, crenças e apoio recebido interrelacionam-se e fornecem uma estrutura para enfrentar as dificuldades que surgem.

Entre os temas discutidos nas reuniões grupais, pelos laringectomizados e seus familiares, destacamos a reabilitação vocal. A cirurgia laringectomia total é considerada mutilatória e, como conseqüência, gera a afonia. A incapacidade de produção do som laríngeo leva a frustrações e diminuição da auto-estima dos indivíduos ${ }^{13,20,22}$.

Embora a reabilitação vocal por meio da voz esofágica seja a mais indicada nos meios médicos brasileiros, ela não é um processo simples, requerendo um esforço motivacional importante, uma rede de apoio eficiente, a atuação de um fonoaudiólogo competente, dependendo também da cicatrização cirúrgica ${ }^{20}$.

A reabilitação vocal do laringectomizado é de responsabilidade do fonoaudiólogo, mas a enfermagem tem um papel importante de fornecer esclarecimentos para o indivíduo e seus familiares, como também de apoiá-lo na realização de exercícios, desde o período de internação até o pós-operatório. Para isso, o enfermeiro deve conhecer o processo, sob o ponto de vista do laringectomizado.

No GARPO, embora haja uma grande expectativa pela aprendizagem da voz esofágica pelos participantes, poucos alcançam êxito no processo e eles enfrentam muitas situações desmotivantes. Buscando compreender este processo, realizamos um estudo de caso onde identificamos que voltar a emitir a voz, para aquele paciente, era "Como se tivesse ganho na loteria". Este

\footnotetext{
* Aluna da Escola de Enfermagem de Ribeirão Preto da Universidade de São Paulo. Bolsista do Programa Especial de Treinamento PET/CAPES

** Enfermeira. Professora Doutora do Departamento de Enfermagem Geral e Especializada da Escola de Enfermagem de Ribeirão Preto da Universidade de São Paulo.Coordenadora do GARPO-Laringectomizados. Orientadora do Estudo
} 
resultado levou-nos a estender o estudo para outros pacientes objetivando "identificar as características do processo de reabilitação vocal entre os laringectomizados, sob o enfoque da cultura".

\section{COMUNiCAÇÃO, CULTURA E A PESSOA LARINGECTOMIZADA}

Segundo ATKINSON \& MURRAY ${ }^{2}$, a comunicação é um meio para os indivíduos de uma organização partilharem significados e compreensão com os outros. É um processo pelo qual uma pessoa transmite seus pensamentos, sentimentos e idéias aos outros, e um instrumento que permite entender e aceitar a outra pessoa, receber ou enviar informações, dar e receber ordens, ensinar e aprender. Esse processo, no entanto, pode ser influenciado por vários fatores, entre os quais a idade, $\mathrm{o}$ momento, o afeto, o sexo, a credibilidade, a atitude e a cultura.

HELMAN ${ }^{11}$ conceitua cultura como um conjunto de princípios (implícitos e explícitos) adquiridos pelos indivíduos enquanto membros de uma sociedade particular. Tais princípios mostram-lhes a forma de ver o mundo, vivenciá-lo emocionalmente e de comportar-se dentro dele, em relação às outras pessoas e ao meio ambiente natural. A cultura também fornece a forma para transmitir estes princípios para a geração seguinte através dos símbolos, linguagem, ritual e artes. Sem essa percepção compartilhada do mundo, a coesão e a continuidade de qualquer grupo humano seria impossível.

$\mathrm{O}$ estudo da cultura procura desvendar os seus componentes como conhecimento, crença, valores, normas e símbolos:

- conhecimento representa as idéias, as abstrações que fundamentam um comportamento, um costume, uma técnica de trabalho;

- crença é a aceitação como verdadeira de uma proposição;

- valores expressam os sentimentos que incentivam e orientam o comportamento humano;

- normas são regras que indicam os modos de agir dos indivíduos em determinadas situações;

- símbolos são realidades físicas ou sensoriais aos quais os indivíduos que os utilizam atribuem valores ou significados; são os gestos, as palavras, os sinais, textos, cantos, vestimentas e outros ${ }^{11}$.

A pessoa laringectomizada é aquela que foi submetida à cirurgia denominada laringectomia total, na qual são removidas as estruturas que produzem o som laríngeo. Esta cirurgia é indicada para a erradicação do câncer de laringe, cuja etiologia está ligada ao consumo de tabaco e bebidas alcoólicas (e seus efeitos combinados), laringite crônica, exposição a gases tóxicos, deficiências nutricionais e predisposição familiar ${ }^{23}$.

Esta cirurgia é considerada um procedimento altamente mutilatório, devido às conseqüências fisiológicas e psicológicas para o paciente ${ }^{12,17,23}$. Entre as conseqüências fisiológicas incluem-se a alteração da via respiratória, traqueostomia permanente, afonia, diminuição da atividade motora do ombro, braço e pescoço; diminuição do paladar e do olfato. As conseqüências psicossociais incluem: alteração da imagem corporal, alteração da comunicação, alteração das atividades sociais e alteração da auto-estima ${ }^{23}$.

A imagem corporal é a imagem que uma pessoa tem de si mesma, estando sujeita a influências tanto físicas como psicológicas; é o fundamento da identidade de uma pessoa, da sua auto-estima ${ }^{13}$.

Quanto à afonia, existem algumas possibilidades de reabilitação vocal, como a emissão da voz esofágica (a menos onerosa e mais utilizada), o uso da laringe eletrônica, a construção cirúrgica de uma fístula tráqueofaríngea para a inserção da prótese de Bloom-Singer, e os meios de menor qualidade como a voz bucal ou faríngea e a mímica labial ${ }^{3,4,20}$.

A afonia e a alteração da imagem corporal modificam social e profissionalmente o modo de vida do indivíduo, causando problemas psicológicos e sociais que poderão fazer com que ele se sinta desmotivado para agir frente às situações, retardando sua reabilitação.

O modo como o indivíduo mantém ou altera seus valores, crenças, conhecimentos, normas e símbolos poderá influenciar a sua motivação ou não para a aprendizagem da voz esofágica e sua adaptação ao contexto familiar, social e profissional, após a cirurgia ${ }^{9}$.

\section{METODOLOGIA}

Para o alcance do objetivo proposto, utilizamos a abordagem metodológica qualitativa proposta por BOGDAN \& BIKLEN ${ }^{4}$.

Participaram do estudo 4 laringectomizados, residentes em Ribeirão Preto-SP; que freqüentavam o GARPO-Laringectomizados, durante os meses de março a setembro de 1997, residentes em Ribeirão Preto-SP. Desses informantes, 3 utilizavam a voz esofágica para comunicar-se e apenas um utilizava a voz faríngea.

Todos os informantes tiveram informações sobre o objetivo e a metodologia do estudo, e concordaram em participar assinando o termo de consentimento.

A coleta de dados foi realizada por entrevista semi-estruturada pela seguinte questão norteadora: Como foi o treinamento da voz esofágica? As entrevistas foram realizadas após as reuniões do grupo e pelo menos uma 
entrevista foi realizada no domicílio, com a participação da esposa.

As entrevistas tiveram duração média de sessenta minutos, foram registradas por gravação e transcritas na íntegra, horas após a sua finalização. Cada entrevista teve duração média de sessenta minutos. A organização dos dados foi realizada através do software "The Ethnograph"

A análise dos dados foi iniciada com a leitura e releitura dos depoimentos. Identificamos segmentos de dados que foram codificados. Após novas leituras e reflexões teóricas sobre os mesmos, os códigos foram reagrupados em categorias temáticas ou de significado.

\section{RESULTADOS E DISCUSSÃO}

\section{A. Caracterização dos informantes}

Os informantes eram do sexo masculino, com faixa etária variando entre 49 e 63 anos; eram casados e as profissões variavam de comerciantes, despachante policial e um operador de máquinas. Apenas o despachante policial ainda mantinha sua atividade profissional parcialmente, sendo que os demais estavam aposentados. Todos haviam sido alcoólatras e tabagistas. O período de pós-operatório variava de dois a quatro anos.

O tempo de treinamento da voz esofágica variou de vinte dias a três meses.

\section{B. Categorias de características culturais da reabilitação vocal}

A análise dos dados desvendou duas categorias que caracterizam a reabilitação vocal, fundamentada nos conceitos culturais. Essas categorias são: o enfrentamento do estigma e o renascer.

\section{B.1. O enfrentamento do estigma}

A afonia e a alteração da imagem corporal (pela presença da traqueostomia definitiva, e afilamento do pescoço, devido ao esvaziamento ganglionar cervical bilateral), são conseqüências pós-operatórias que estigmatizam os laringectomizados. O estigma é percebido por eles e, como mecanismo de defesa, alteram seus hábitos de vida. Como para compensar, desenvolvem outros comportamentos que passam a ser considerados de forma valorativa.

Assim, a primeira repercussão do estigma atinge a atividade profissional. Com exceção de um paciente, que se afastou parcialmente de seu trabalho, todos os outros abandonaram suas atividades laborais. Esta perda de função é lamentada por todos:
"Pior foi ficar sem trabalhar!".

"Minha preocupação depois da cirurgia era voltar a trabalhar".

"Agora eu sou aposentado..."

"Ele queria trabalhar, fazer alguma coisa, voltar a ser gente...”(esposa)

A primeira justificativa dos informantes para o abandono da profissão deu-se ao estigma dos outros, pela sua condição de estar afônico. Esse estigma foi sentido por todos os informantes, relacionado ao contexto de trabalho e nas situações do dia a dia.

"Tem muita rejeição, teve um amigo meu que virou o rosto e o nariz quando eu fui falar com ele. As pessoas têm medo da doença, pensa que é assim e que pega pelo ar'”.

“... foi por causa do preconceito das pessoas".

"As pessoas não iam me dar um emprego comigo desse jeito!".

"As pessoas olhavam assim ...e se afastavam”.

O laringectomizado percebe não apenas o estigma que parte dos outros, mas entre os seus próprios familiares:

"Aqui em casa mesmo, teve gente que ficou meio assim..., dava pra sentir uma certa rejeição".

Segundo os informantes, o afastamento do trabalho e a aposentadoria precoce ocorreram por recomendação médica (quando o seu trabalho ocorria em um ambiente insalubre), pela dificuldade de comunicação (por se tratar de um trabalho que envolve relações pessoais, como no comércio) e também pela insistência da família para a aposentadoria.

O estigma social dos laringectomizados é abordado na literatura. GREER \& MOOREY ${ }^{10}$ foram alguns dos pesquisadores que detectaram que os pacientes não voltavam às suas atividades profissionais, mesmo estando fisicamente bem. Para REDKO ${ }^{18}$ quando os pacientes optam pela aposentadoria, mesmo que desnecessariamente, eles acreditam que esta é a melhor maneira de evitarem uma recidiva do câncer. ZAGO et al. ${ }^{24}$ identificaram que a família tem um papel decisivo no abandono da profissão pelo paciente, fundamentada numa atitude de superproteção para com ele. BOLTANSKI $^{5}$ salienta que enquanto o indivíduo consegue manter seu desempenho social, representado principalmente pelo trabalho, ele não se vê como pessoa doente sendo que a percepção da doença está quase sempre associada com a disposição para trabalhar. Assim, quando há perda da força de trabalho, há falta de disposição do indivíduo para sair ou passear. 
Consequentemente, o desempenho social é um fator adicional, que predispõe ao isolamento social, como foi identificado por ZAGO et al. ${ }^{24}$.

A afonia é uma condição não aceita pelo laringectomizado, principalmente no primeiro ano de pósoperatório. Portanto, é preciso buscar alguma alternativa de comunicação para conviver com a situação. As alternativas são limitadas; para os que têm capacidade de escrever, a escrita é a opção. Para aqueles que não tem essa capacidade, a comunicação se processa unicamente através da mímica labial.

"Só por escrito, porque os outros não entendiam a mímica".

"Eu fiquei dez meses sem falar nada, só escrevendo. Agora você imagina quem não sabe escrever... como é que fica!".

A expectativa pela possibilidade da emissão da voz esofágica inicia no período de internação hospitalar. Enquanto essa expectativa não se concretiza, o laringectomizado busca motivação para conviver com o seu cotidiano. Com a mudança de valores que a condição de doença crônica em geral acarreta, o indivíduo procura ajudar outros pacientes, recém-operados, a conviverem com suas condições:

"Eu já prontifiquei de ir lá (no hospital) falar com eles antes e depois da cirurgia".

"Eu gosto de ir lá (no hospital), conversar com quem tá com dificuldades...".

TRENTINI \& PACHECO ${ }^{21}$ observaram que a ajuda entre pessoas ostomizadas contribui para minimizar as preocupações, os problemas e evitar o isolamento social.

Frente à percepção do estigma pela afonia, a possibilidade da reabilitação vocal é apresentada como uma esperança:

"A chance de aprender a voz esofágica era uma esperança".

WHITE et al. ${ }^{22}$ comentam que as mudanças e perdas causadas por uma doença, cirurgia ou situação de crise, alteram o estado psicológico e, consequentemente, as atividades sociais.

Para OLESON \& $\mathrm{KING}^{16}$ a recuperação da capacidade de falar é uma expectativa de reassumir a função social, visto que a comunicação verbal-oral é culturalmente compartilhada como natural na sociedade ocidental. DeSANTO et al. ${ }^{7}$, no entanto, ressaltam que a qualidade da voz não é o fator primariamente determinante na qualidade de vida. $\mathrm{O}$ autor ressalta que qualidade de vida e qualidade da fala não são as mesmas, ainda que alterações na fala podem levar a uma qualidade de vida satisfatória.

Além do estigma pela afonia, os pacientes apontaram o estigma dos outros à sua imagem corporal alterada. Esse estigma apresenta-se na forma de reações dos próprios pacientes e as reações das outras pessoas à sua imagem alterada:

"No começo, antes da operação, eu fiquei meio assim..., mais ai eu pensei: se tem que ser assim, eu vou conseguir".

"Ah, na hora tudo é muito dificil, você fica até sem saber".

"Sinto até hoje. Foi muito triste, muito pesado".

"É muito duro".

Apenas um dos informantes referiu não ter tido uma reação de rejeição à sua imagem pois mantinha relações com outros laringectomizados, quando soube do seu diagnóstico. Para ele, a imagem corporal já era conhecida e esperada:

"Não fiquei desesperado porque eu tinha dois amigos antigos que operaram uns dois anos antes. Então, eu sabia que não ia mais falar, que ia ficar com esse buraco, mas tinha a chance de falar de outro jeito".

A reação dos indivíduos laringectomizados à percepção do estigma varia entre a revolta, o medo e a desconsideração do fato. Essa reação parece estar ligada ao modo como a pessoa vê sua vida em relação à sociedade e a valorização das suas relações, sob os padrões culturais vigentes. Em geral, aqueles que sofrem menos com o estigma, dão menor valor às opiniões, possuem uma vida social que mais se aproxima da que tinham antes da cirurgia:

"Ficava desanimado, chorava. Ficava imaginando porque as pessoas me tratavam daquele jeito, como se fosse bobo".

"Ele ficava trancado treinando porque tinha medo da gente rir"(esposa).

"Nunca dei muita importância no que as pessoas falavam, eu acho que isso ajudou bastante".

"Eu sempre fui uma pessoa que não dava muito valor para a opinião dos outros".

Essas falas referem-se ao enfrentamento da afonia e da alteração da imagem corporal. Entretanto, esses dois aspectos não podem serem tratados isoladamente. Segundo DeSANTO et al. ${ }^{7}$; DEVINS et al. ${ }^{9}$, muitos pacientes apresentam dificuldade de aceitação social devido ao estoma, mesmo após a aquisição da voz esofágica com qualidade satisfatória.

Ameaças à imagem corporal podem romper não somente as atividades usuais da vida, como adversamente afetar suas relações com outras pessoas, incluindo as mais significativas. Desse modo, a alteração da imagem corporal pode alterar as respostas sociais do paciente e levar a estigmatização. A estigmatização pode ocorrer por uma perda de parte do corpo de modo similar à que ocorre quando uma pessoa morre. Em uma cirurgia 
mutilatória, como na laringectomia total, o indivíduo pode ser atingido pela rejeição e separação dos amigos ou pessoas queridas. Entretanto, esses sentimentos podem ser dissipados quando o indivíduo reintegra as alterações à sua imagem corporal total ${ }^{13}$.

Para SHIPES ${ }^{19}$, as normas culturais requeridas pela sociedade ocidental para uma pessoa ser aceita são: juventude, saúde, perfeição e totalidade funcional. A expectativa da sociedade é que as pessoas sejam perfeitas e livres de odores. NOVAES ${ }^{15}$ acrescenta que a deformidade física é mais sensivelmente percebida pelo sexo masculino e a suscetibilidade aumenta com a idade. Desse modo, os laringectomizados que são na sua maioria homens acima de 50 anos de idade, percebem e sentem mais intensivamente a imagem corporal alterada.

O resultado da alteração da imagem corporal e a reação à ostomia e ao diagnóstico podem sufocar a pessoa, tornando-a "imobilizada" para as situações ${ }^{19}$. Além disso, podem ser um fator desmotivante para a aprendizagem da voz esofágica e para a reabilitação geral. Para a autora, a reação positiva de outras pessoas ao laringectomizado facilita o seu ajustamento ao novo modo de vida.

Para DEVINS et al. ${ }^{8}$ a percepção negativa do estigma atribuído à perda da voz e à desfiguração do corpo, produzidos pela laringectomia, podem diminuir a freqüência de experiências interpessoais positivas, minimizando a auto-estima do indivíduo.

\section{B.2. O renascer}

Nessa categoria foram agrupados os dados relacionados às expectativas durante o treinamento e na recuperação da voz.

Dentre todos os entrevistados apenas um avaliou o treinamento como sendo fácil. Para os demais, o processo foi permeado por dificuldades:

"É fácil! Como eu disse precisa de força de vontade".

"Foi muito cansativo".

"Muito dificil".

"Foi cansativo".

A motivação para o treinamento da voz esofágica derivou do desejo de voltar a comunicar-se oralmente e a vontade própria, refletindo uma atitude interna dos indivíduos:

"Vontade de falar novamente".

"Eu sempre tive muita força de vontade, queria muito, sabia que ia conseguir”.

"Primeiro de tudo é preciso querer voltar a falar. Eu queria e disse para mim: eu vou voltar a falar".

"Queria e falei".

$\mathrm{O}$ apoio familiar e a observação de outros pacientes já reabilitados associam-se à motivação exposta acima:

"Depois minha família sempre esteve do meu lado, me dando força em que eu precisava, porque a família é a única coisa que a gente tem, se eles abandonam a gente quando a gente mais precisa, então a gente desanima".

"A família... eles me ajudaram muito".

"Eu via meus amigos conversando, levando uma vida normal, um deles continuava carregando caixa de frutas nas costas e dirigia caminhão. Isso me ajudava, era estímulo!".

"Quando eu vi o seu Joaquim e o seu Luís falando, eu pensei comigo; se eles podem eu também posso ... e ficava treinando".

"Minha família, porque a família sempre está em primeiro lugar".

Tendo motivação, superada as dificuldades do treinamento, o paciente consegue emitir os primeiros sons. A recuperação da voz é sentida como um momento de glória, de renascer:

"É como se tivesse ganho na loteria!".

"Eu nem sei,... foi muito bom,... como se o mundo se abrisse pra mim”.

"Foi muito, muito bom. Eu fiquei muito contente, nem sei... é como sentir-se nascendo de novo, uma sensação de que posso...".

"Na hora a gente nem sabe. É só uma satisfação muito grande".

"Estar começando a falar dá uma força!"

"Eu já cheguei a ensinar dois conhecidos meus a falar!".

O retorno da emissão da voz é um dos objetivos mais almejados no processo de reabilitação do paciente laringectomizado. É a expectativa em reassumir o papel social, segundo os seus padrões socioculturais. Assim, a valorização cultural da voz é um aspecto predominante em sua reabilitação, no seu ajustamento e na sua qualidade de vida. Outros fatores também interferem nesse processo como a extensão da cirurgia, a visita pré-operatória de outros laringectomizados, as seqüelas da radioterapia, a dor crônica, a habilidade em usar outra forma de comunicação e a satisfação do paciente com o suporte social recebido ${ }^{14}$.

A participação da família, principal rede de suporte social no processo de reabilitação, é de grande importância. O seu equilíbrio entre o apoio e a superproteção, possível quando se tem o conhecimento das reais limitações, aliado ao apoio de outros ostomizados e de profissionais (como o GARPO), 
contribui para minimizar as preocupações, a solucionar os problemas e a evitar o isolamento social ${ }^{9,19,21}$.

\section{A reabilitação vocal sob a lente cultural}

Com os resultados deste estudo identificamos que a reabilitação vocal tem como significado: "nascer de novo". Com esta expressão, os laringectomizados pacientes enaltecem a valorização cultural da comunicação verbal-oral. Sentir-se nascendo de novo, é ter o privilégio de voltar ao convívio do seu grupo social, de estar próximo à condição de normalidade anterior a cirurgia; é poder provar suas capacidades perante as situações de estigmatização. Nesse significado, apreendemos a valorização cultural da voz orientando o comportamento do laringectomizado, procurando tornálo novamente aceito pelo seu grupo sócio-cultural.

Porém, a reabilitação vocal não é um processo simples. Ele é permeado por situações de desmotivação e dificuldades, exigindo persistência, força de vontade e busca de alternativas para conviver com as diferentes situações ${ }^{9}$. É um processo influenciado pelas características pessoais de enfrentamento da afonia e da imagem corporal alterada, das suas crenças, valores e símbolos, como também das pessoas com quem convive.

O apoio familiar foi referido como sendo de grande relevância durante o processo de reabilitação vocal e para o enfrentamento das dificuldades. Aqueles pacientes que possuem um apoio familiar efetivo sofrem menos com o problema do estigma e conseguem evitar o isolamento social.

Além do apoio familiar, a reabilitação do paciente requer a compreensão e o apoio dos profissionais de saúde no sentido de acentuar suas potencialidades e minimizar suas limitações, ajudando-o a recuperar seus sentimentos de auto-estima positiva. Por outro lado, a reconquista da capacidade de emissão da voz é o principal objetivo da reabilitação pelo paciente, porém não o único.

O GARPO, enquanto grupo de apoio, tem procurado otimizar o processo de reabilitação vocal e geral dos laringectomizados por meio de uma atuação efetiva desde o período de internação do paciente, incentivando a participação dos familiares em todos os momentos do processo.

Os resultados deste estudo corroboram os de outros pesquisadores. AGUILLAR ${ }^{1}$ relata que o treinamento da voz esofágica é demorado, exige persistência e os estímulos contextuais representados pelo apoio dos familiares poderá determinar uma adaptação positiva. Entretanto, o processo de readaptação social também apresenta dificuldades, principalmente no que tange ao trabalho, lazer e ao relacionamento sexual.

É importante que se trate da questão da reabilitação vocal dentro de um contexto de reabilitação psicológica, social, profissional, estética e funcional, pois a perda da voz pela laringectomia representa para o indivíduo não apenas a agressão ao seu órgão fonatório, mas, também, a ameaça a sua integridade e sua integração biopsicossocial.

\section{CONSIDERAÇÕES FINAIS}

Este trabalho, que se originou a partir do interesse despertado por um estudo de caso realizado anteriormente, teve como objetivo identificar as características da reabilitação vocal pelos laringectomizados, sob o enfoque da cultura.

A cultura é um fenômeno que integra uma série de aspectos que influenciam a reabilitação, positiva ou negativamente. Com este enfoque, a reabilitação vocal pôde ser compreendida pelo tema "nascer de novo". Com essas palavras, o laringectomizado manifesta a sua valorização cultural do retorno da vocalização. Essa compreensão emergiu a partir de duas categorias de características culturais: o enfrentamento do estigma e o renascer.

Entretanto, a reabilitação vocal é apenas uma das etapas da reabilitação social do laringectomizado. $\mathrm{Na}$ nossa experiência no GARPO- Laringectomizados, percebemos que a reabilitação vocal é um ponto chave para o paciente buscar elementos internos da sua percepção de ser humano e aplicá-los no seu cotidiano para a integração familiar e social.

Por outro lado, sabemos que nem todos os laringectomizados conseguem reabilitar-se vocalmente, seja por problemas fisiológicos ou psicológicos. Por exemplo, com base na nossa experiência no GARPO, no período de um ano, apenas 6 de 25 participantes conseguiram desenvolver a emissão do som esofágico.

Uma das possibilidades de apreendermos como esses problemas estão influenciando a reabilitação do paciente é através da identificação dos elementos culturais que direcionam os comportamentos, sentimentos e valores, que foi a finalidade deste estudo.

É fundamental para a equipe de enfermagem procurar identificar as características culturais que permeiam e influenciam a reabilitação vocal para que se possa prestar uma assistência efetiva ao paciente e à sua família. Por assistência efetiva consideramos as ações que o enfermeiro deve implementar, junto com o fonoaudiólogo, para que sejam supridos todos os recursos possíveis, num menor período de tempo, para que o laringectomizado possa "nascer de novo". 

THE PROCESS

The objective of this study was to identify the characteristics of the process of vocal rehabilitation among laryngectomees focusing on culture. The study included four laryngectomees who attend the GARPO-Laryngectomees (Support Group For The Rehabilitation of Ostomized Patients - Laryngectomees) and communicate with esophageal or pharyngeal voice. The theme that emerged from the data was "to be born again", in agreement with the cultural value of the voice in our society. The study revealed as well the difficulties of the process, the importance of family participation and the stigma of the altered body image.

KEY WORDS: vocal rehabilitation, laryngectomized patient, esophageal voice

\section{REHABILITACIÓN VOCAL DE LOS LARINGECTOMIZADOS: CARACTERÍSTICAS CULTURALES DEL PROCESO}

El objetivo de este estudio fue identificar las características del proceso de rehabilitación vocal entre los pacientes laringectomizados, sobre el enfoque de la cultura. Participaron del estudio cuatro pacientes del GARPO-Laringectomizados (Grupo de Apoyo y Rehabilitación de los Pacientes Ostomizados - Laringectomizados) y que se comunican con la voz esofágica o faríngea. El tema principal de la entrevista fue "nacer de nuevo". Con esta frase el paciente sintetizó la valoración cultural de la voz dentro del patrón cultural vigente en la sociedad. El estudio reveló las situaciones de dificultad, la importancia de la familia y el proceso de enfrentamiento del estigma de la imagen corporal alterada y de la afonía.

TÉRMINOS CLAVES: rehabilitación vocal, paciente laringectomizado, voz esofágica

\section{REFERÊNCIAS BIBLIOGRÁFICAS}

01. AGUILLAR, O.M. Contribuição ao estudo do processo de adaptação da pessoa laringectomizada. Ribeirão Preto, 1984. 110p. Tese (Mestrado) - Escola de Enfermagem de Ribeirão Preto, Universidade de São Paulo.

02. ATKINSON, D.L.; MURRAY, E.M. Fundamentos de enfermagem. Rio de Janeiro: Guanabara, 1985. p.56-59.

03. BLALOCK, D. Speech rehabilitation after treatment of laryngeal carcinoma. Otolaryngol. Clin. North Am., v. 30, n. 2, p. 179- 88, 1997.

04. BOGDAN, R.; BIKLEN, S. Investigação qualitativa em educação: uma introdução à teoria e aos métodos. Porto: Editora Porto, 1994.

05. BOLTANSKY, L. As classes sociais e o corpo. Rio de Janeiro: Graal, 1994.

06. CASSIANI, S.H.B.; ZAGO, M.M.F. A análise de dados qualitativos: a experiência no uso do "The Ethnograph". São Paulo. Acta Paul. Enfermagem, v. 10, n. 1, p. 100-6, 1997.

07. DeSANTO, L.W. et al. Quality of life after surgical treatment of cancer of the larynx. Ann. Otorhinol. Laryngol., v. 104, p. 763-9, 1995.

08. DEVINS, G.M.; STAN, H.J.; KOOPMANS, J.P. Psychosocial impact of laringectomy mediated by perceived stigma and illness intrusiveness. Can. J. Psychiatry, v. 39, p.608-16, 1994.
09. FLÁVIO, P.G.C.; ZAGO, M.M.F. Como se tivesse ganho na loteria: o significado da reabilitação vocal na visão de um paciente laringectomizado. Rev.latino-am.enfermagem, v.5, n. 3, p. 19-25, 1997.

10. GREER, S.; MOOREY, S. Adjuvant psychical therapy for patients with cancer. Eur.J.Sug.Oncol., v. 13, p. 1-6, 1987.

11. HELMAN, C.G. Cultura, saúde e doença. Trad. Eliane Mussnich. Porto Alegre: Artes Médicas, 1994.

12. KEDDIE, M. Total laryngectomy for advanced carcinoma of the larynx. Nurs.Times, v. 14, n. 11, p.1155-7, 1981.

13. McCONELL, E.A. Clinical considerations in perioperative nursing: aspects of care. Philadelphia: J.B.Lippincott, 1987.

14. MATHIESON, C.M.; STAM, H.J; SCOTT, J.P. Psychosocial adjustment after laryngectomy: a review of the literature. J. Otoryngol., v. 10, n. 5, p. 331-6, 1990.

15. NOVAES, M.H. Psicologia aplicada à reabilitação. Rio de Janeiro: Imago, 1975.

16. OLESON, M.; KING, T.W. Back to the beginning case management of the older client with laryngeal speech needs. J.Gerontol.Nurs., v. 16, n. 12, p. 27-9, 1989.

17. OTTO, S.E. Oncology nursing. St. Louis: Mosby, 1991. 
18. REDKO, C.P. Representações da doença dos pacientes com câncer de cabeça e pescoço. Acta Oncol.Bras., v. 14, n. 5, p. 231-7, 1994.

19. SHIPES, E. Psychosocial issue: the person with ostomy. Nurs.Clin.North Am., v. 22, n. 2, p. 291302, 1987.

20. STEFFEN, N. Reabilitação vocal após laringectomia: experiência pessoal. In: BRANDÃO, L.; FERRAZ, A.R. Cirurgia de cabeça e pescoço: princípios técnicos e terapêuticos. São Paulo: Roca, 1989. v. 2, p. 355-69.

21. TRENTINI, M.; PACHECO, M.A. Vivendo com um estoma: um estudo preliminar. Rev. Gaúch. Enfermagem, v. 13, n. 2, p. 22-8, 1992.
22. WHITE, N.E.; RITHER, J.M.; FRY, C. Coping, social support, and adaptation to chronic illness. West J.Nurs.Res., v. 14, n. 2, p. 211-4, 1992.

23. ZAGO, M.M.F. Plano de ensino para o preparo da alta médica do paciente laringectomizado. Ribeirão Preto, 1990. Dissertação (Mestrado) Escola de Enfermagem de Ribeirão Preto, Universidade de São Paulo.

24. ZAGO, M.M.F.; STOPA, M.J.R.; MARTINEZ, E.L. Ser laringectomizado. In: SEMINÁRIO NACIONAL DE PESQUISA EM ENFERMAGEM, 8., Ribeirão Preto. 1995. Programa e Resumos. Ribeirão Preto: Associação Brasileira de Enfermagem, 1995. p. 118. 